\title{
Nova Scotia nurse practitioners understanding of inappropriate prescribing and using a prescribing evaluation tool: A pilot study
}

\author{
Rena Creedon ${ }^{* 1}$, Stepehn Byrne ${ }^{2}$, Ingrid Sketris ${ }^{3}$, Julia Kennedy ${ }^{4}$, Suzanne McCarthy ${ }^{2,5}$ \\ ${ }^{1}$ School of Nursing and Midwifery, University College Cork, Cork, Ireland \\ ${ }^{2}$ Pharmaceutical Care Research Group, School of Pharmacy, University College Cork, Cork, Ireland \\ ${ }^{3}$ Pharmacy Department, Dalhousie University, Halifax, Canada \\ ${ }^{4}$ Pharmacy Department, Otago University, Dunedin City, New Zealand \\ ${ }^{5}$ Pharmacy Department, Cork University Hospital, Cork, Ireland
}

Received: August 20, 2015

DOI: $10.5430 /$ jnep.v6n4p21
Accepted: November 1, $2015 \quad$ Online Published: December 8, 2015

URL: http://dx.doi.org/10.5430/jnep.v6n4p21

\begin{abstract}
Background and Objective: Over the past two decades nurse practitioners' prescriptive authority, has evolved specifically in response to pressures from patients' physicians, changing policies and preoccupation with the effectiveness and efficiency of care. However, little is known of the nurse practitioners' understanding of appropriate and inappropriate prescribing and their views of using a prescribing evaluation tool in practice to ensure prescribing is optimal and can support national change. The aim of this research is to explore Nova Scotia nurse practitioners (with prescriptive authority) understanding of inappropriate prescribing and their experience of using a prescribing evaluation tool.

Methods: This qualitative study used a phenomenology research design. A series of semi-structured telephone interviews were held with a purposive sample of nurse practitioners with prescriptive authority. Interviews were tape recorded and transcribed verbatim. Data were analysed using Colaizzi's framework method.

Results: The study identified four recurrent themes: competence and confidence, understanding inappropriate prescribing, consequences of inappropriate prescribing and the role screening tools play in prescribing.

Conclusions: The potential for prescribing nurse practitioners to contribute positively to address the issues with increasing healthcare demands and associated problems and to improve quality of care in the Canadian health system is substantial given their insight to medication management.
\end{abstract}

Key Words: Nurse practitioner, Prescribing, Inappropriate prescribing, Prescribing evaluation tool, Quality care

\section{INTRODUCTION}

Nurse practitioner has no universal definition ${ }^{[1]}$ but it is generally accepted that nurse practitioners provide services to individuals and families across the lifespan and work in a variety of community-based settings. ${ }^{[2,3]}$ The title is frequently used to identify advanced practice nursing in Canada, the
United States (US), Australia and the United Kingdom (UK). In Ireland, the position is referred to as an Advanced Nurse Practitioner (ANP). Historically, the nurse practitioner role was introduced in the US in the mid-1960s ${ }^{[4]}$ and Canada in $1967^{[2]}$ to meet increasing health service needs, with the literature describing the first reported nurse practitioner's

*Correspondence: Rena Creedon; Email: r.creedon@ucc.ie; Address: School of Nursing and Midwifery, University College Cork, Cork, Ireland. 
role as "a contentious issue that produced a good deal of conflict and anxiety" at the time. ${ }^{[5]}$ Today however, the role encompasses an evidence-informed holistic approach that emphasises health promotion and partnership development, that complements rather than replace other healthcare providers. ${ }^{[6]}$ More recent events of physician shortage, together with the aging population and the associated increase in healthcare demands that has exerted considerable pressure on the Canadian health care system ${ }^{[7]}$ and so nurse practitioners have become increasingly identified as a resource that can meet the ongoing health need of the Canadian population. ${ }^{[8]}$

Nurse practitioner's prescriptive authority has therefore evolved in response to pressures from patients, physicians, changing policies and requirements relating to the effectiveness and efficiency of care. ${ }^{[9,10]}$ Prescribing authority for Canadian nurse practitioners is particularly important because health services cover large geographical regions that are remote, sparsely populated and where medical practitioners are not readily available. ${ }^{[11]}$ However, prescriptive authority for nurse prescribers in the Canadian context is complex and may vary due to provincial and territorial governance systems within the country. ${ }^{[1]}$ This has resulted in each province and territory having its own approach to nurse practitioner positions with prescriptive authority closely linked to the development of the role within each province. The common ground being the requirement for additional education, training, and regulation to ensure that those functioning in the nurse practitioner role are able to provide safe care to the public. ${ }^{[6]}$

Internationally over the past decade nurse practitioners have become part of the long term care system ${ }^{[12-14]}$ and are now caring for clients with higher prevalence of chronic illness, disability and dependency. ${ }^{[15]}$ However, advancing age and exposure to medications increases the risk of contact with a potentially inappropriately prescribed medication and development of complications from drug therapy. More specifically, the literature describes inappropriate prescribing as encompasses the use of medicines that pose more risk than benefit to patients, the use of medicines that have clinically significant drug-drug and drug-disease interactions, and importantly, the under-use of beneficial medicines. ${ }^{[16]}$ Consequently, particular care must be taken when determining drugs and dosages for this section of the population to ensure prescribing is appropriate considering the long standing issues and number of older adult clients in receipt of medicines for chronic conditions in the Canadian health service. ${ }^{[17]}$ While the benefits of pharmacotherapy for the older adult are potentially substantial, the process of choosing the appropriate medicine for the individual older adult patient may be complex. Changes in the patient's medical status over time can cause long-term medicines to become unsafe or ineffective, therefore part of the nurse practitioner's role is regular medication review to ensure continuing positive benefit for each medicine prescribed for the older adult. To ensure medication benefits are maintained several validated tools have been developed to help prescribers identify potential inappropriate prescribing in older adult care. ${ }^{[16,18,19]}$ The significance of appropriate prescribing is best viewed in the context of the financial cost to the health service which has been identified by the Canadian Institute of Health Information (CIHI). In 2013, an estimated $\$ 34.5$ billion was spent on drugs, the majority of which $\$ 29.3$ billion (85.0\%) was spent on prescribed drugs. ${ }^{[20]}$ Within the priority research area of Drug Policy, the Canadian Institute of Health Research has identified effectiveness, safety and adverse events as key areas to be addressed, their vision being to "transform from a reactive, one-size-fits all approach to a more personalized system of predictive, preventive, and precision healthcare that is tailored to a population or an individual". ${ }^{[21]}$ Incorporating nurse practitioners to provide direct care by way of "initial diagnosis of problems/concerns, establishing of diagnosis following appropriate diagnostic tests if required and formulation of a management plan, which may include prescriptions of medications" ${ }^{\text {"[2] }}$ has the ability to provide personalised appropriate care the initiative requires. Furthermore, the competence of nurse practitioners to manage patient care in a comparable manner to physicians, with high levels of patient satisfaction, combined with increased advice on education and health promotion has been well reported in the international literature. ${ }^{[23-27]}$ However, the literature in relation to nurse practitioners understanding of appropriate or inappropriate prescribing is limited; leaving a void in our understanding of the impact nurse practitioners with prescriptive authority may have on patients' drug regimes. The difficulty however, can be local governance policy that limits the number of products available in the prescribing formulary for nurse practitioners ${ }^{[28]}$ causing restrictions on prescribing that impact on their ability to prescribe appropriately. Therefore, it is important to gain a better appreciation of Canadian nurse practitioners' understanding of appropriate and inappropriate prescribing and their views of using a prescription evaluation tool in practice to ensure prescribing is optimal and can support the planned national change.

\section{Aim}

The aim of this research is to explore Nova Scotia nurse practitioners (with prescriptive authority) understanding of inappropriate prescribing and their experience of using a prescribing evaluation tool. 


\section{METHOD}

This study adopted a Husserlian, or descriptive, phenomenology approach to the research. Data were collected in May 2015 during a research travel bursary visit to Dalhousie University, in Halifax. Using a descriptive phenomenology approach is the most appropriate way to develop an understanding of nurse practitioners' experience of appropriate and inappropriate prescribing and importance placed on a prescribing evaluation tool as interpreted by nurse practitioners who have lived the experience. An important component of Husserlian phenomenology is the belief that it is essential for the researcher to shed all prior personal knowledge to grasp the essential lived experiences of those being studied.

\subsection{Participants}

Participants in a Husserlian phenomenology study must have experienced the phenomenon and be able to articulate what it is like to have lived that experience ${ }^{[29]}$ of using a medication evaluation tool in practice. Therefore, a purposive sample of nurse practitioners with prescriptive authority working with older adult care in the greater Halifax region and the wider area of Nova Scotia, Canada were asked to participant. Sampling continued until no new themes emerged, this oc- curred after eight interviews. All participants except one was female, experience as nurse practitioners with prescriptive authority ranged from 2 to 14 years. All of the nurse practitioners interviewed were primary healthcare practitioners, with seven of them currently working in community health centres and one in private practice supported by a health care team.

\subsection{Interviews}

Participants were first contacted by email to establish their interest in participating in the research. Positive responses were followed up with personal emails that included interview details and requesting that the participant identify a date and time suitable to carry out a telephone interview. Telephone interviews were necessary because of the diverse geographical location of participants across the state of Nova Scotia, Canada and the time frame available to the researcher to collect the data. Interviews followed a structured process to ensure appropriate structure and accurate preparation for the interviews, the process was divided into three: a) before, b) during and c) after the interview, details of which are set out in Table 1.

Table 1. Telephone interview protocol

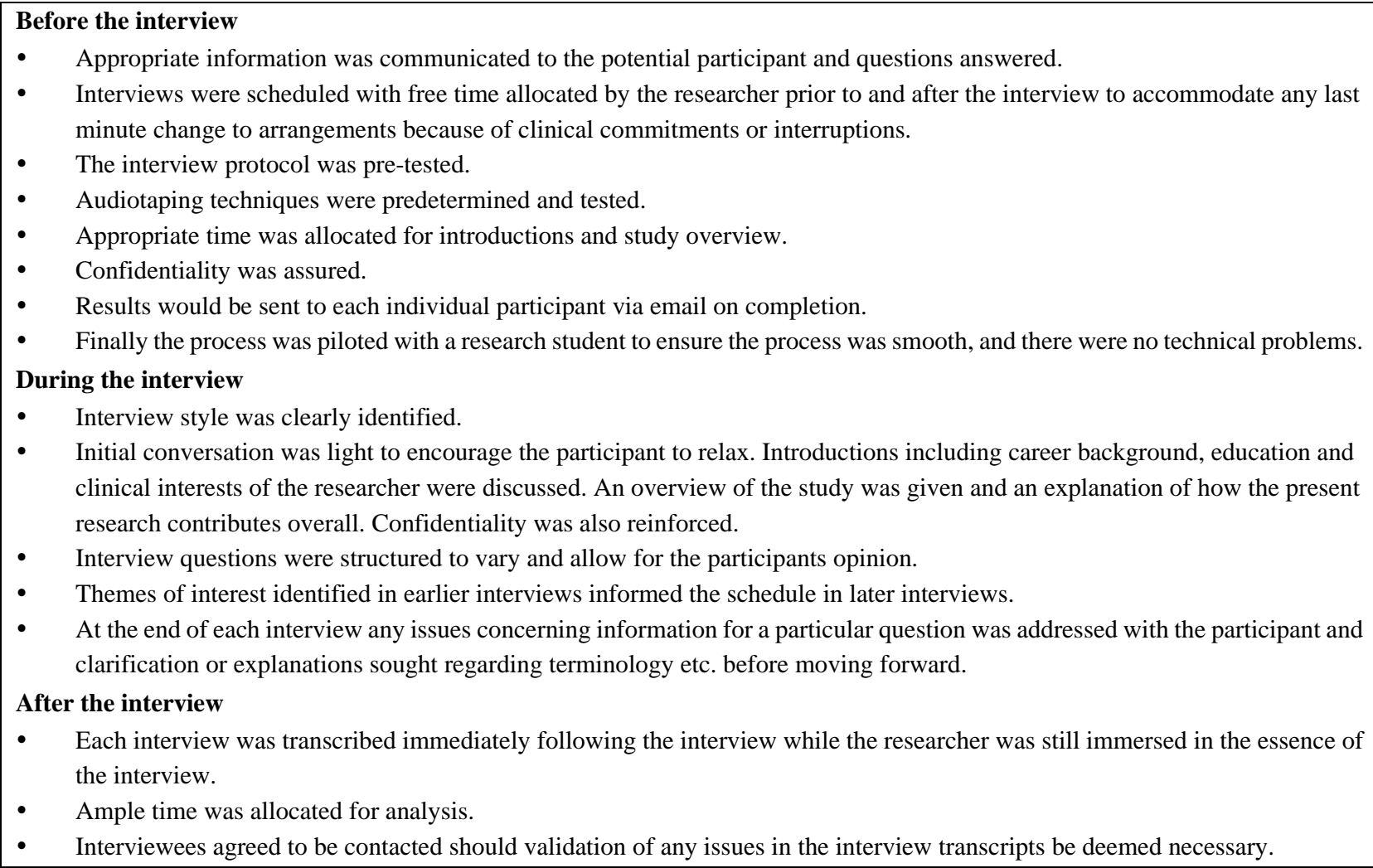




\subsection{Data collection}

Before the interview process commenced, research participants were given the opportunity to ask the researcher questions regarding the study. Verbal consent was obtained and the possibility of re-negotiating consent was also discussed. Confidentiality was assured and the right to withdraw at any time during the investigation, without prejudice, was guaranteed.

Interviews were conducted by telephone with each practitioner for approximately 25-35 mins. A predetermined set of open questions were used to maintain focus on appropriate and inappropriate prescribing and the value of using a prescription evaluation tool. This topic guide was developed by the author for a previous study using STOPP/START and piloted to ensure the guide maintained focus on appropriate and inappropriate prescribing. This structure provided an outline for the interview however, additional questions were allowed to emerge naturally from the dialogue. Due to the lack of visual cues the researcher took notes as a reminder of the non-verbal communication such as pauses or hesitations that took place during the interview to facilitate transcription.

The interviews were digitally recorded and transcribed immediately following the interview to ensure the experience as described by the participant was accurately captured. Using the telephone for data collection interviews may also reduce some forms of response bias (facial expressions) as the interviewer and participant are potentially less affected by each other's presence. This, in turn, may increase the level of comfort for both parties and result in a more relaxed interview. ${ }^{[30]}$

\subsection{Ethical considerations}

Access to potential participants for the study in Canada was facilitated by the Pharmacy Department at Dalhousie University who arranged the appropriate meeting and introduction to the Senior Advanced Nurse Practitioner in Nova Scotia to discuss the study. Before the interview process commenced, research participants were given the opportunity to ask the researcher questions regarding the study. Verbal consent was obtained and the possibility of re-negotiating consent was also discussed. Confidentiality was assured and the right to withdraw at any time during the investigation, without prejudice, was guaranteed.

\subsection{Data analysis}

Data analysis was carried out using Colaizzi's (1978) Procedural Steps ${ }^{[31]}$ which provided a framework in keeping with phenomenological research. Meaning statements were clustered into common themes and again referred back to the original commentary for validation, thus ensuring that only the participant's perception was captured.

In following the principles of data reduction all themes were included until a textural-structural description of the experiences of the nurse prescribers as a whole was obtained. It was necessary to recognise overlapping themes and clarify others that were ambiguous by bringing them back to the participant for validation or further elaboration, when necessary. In doing this, the interpretive research moved back and forth between two worlds: that of the understanding and resourceful dwelling of the participants, and the distancing and questioning world of the researcher. Through analyses and interaction with the data, it is hoped to progress beyond the common sense understanding of the participants' experience in the situation under study to a level of interpretation and critique. ${ }^{[32]}$

\section{RESUltS}

Following analysis of the narrative data, findings were grouped under the following headings for reporting:

- Level of confidence and competence described by nurse practitioners in their role as prescriber.

- Understanding and consequences of inappropriate prescribing.

- The role screening tools play in prescribing for older people.

\subsection{Confidence and competence}

Participants acknowledged that having prescribing rights had improved their self-esteem, and autonomy in practice. When asked specifically to rate their confidence in prescribing on a scale of 1-10, 1 being the least and 10 the most confident the majority of participants rated themselves between 8 and 10. These participants were well established having the most experience in their specialty area, kept up to date and understood their professional boundaries. However, one participant did not share this view awarding themselves a 6 . This participant had the least experience and attributed this to not having had the opportunity to prescribe as part of the education process.

"You know I found when you get in a course you can teach about the disease and learn about a particular drug but we don't know how to prescribe or how to titrate or discontinue it (medication) really I find you learn by using the drug or talking to colleagues... I didn't know how to, start it (prescribing) and I always 'start low and go slow'. But what is low and what is slow?" (Participant 2) 
Additional, issues concerning confidence and competence surfaced when asked if there was anything they should know more about when prescribing for older adults. CPD was identified by all participants as important to maintain awareness of medication issues and better placing them to question or challenge medication changes or adjustments required.

"I won't prescribe anything new unless I have absolute understanding of what patients are on and taking in addition, like herbal over the counter or any complementary therapies. . . because a lot of them don't even think that an enteric coated aspirin they take for heart disease is even a medication because they don't get a prescription for it... patients adding over the counter medications can be a big problem." (Participant 7)

Accurate assessment was also identified as important for competent prescribing. However, several participants highlighted that developing nursing expertise in a particular area can focus your knowledge so finely that limitations can occur.

"I'm comfortable assessing my patients, my background is renal but my patients don't just come with renal problems they have vascular problems, diabetes the whole list. I'm not an expert in some of those other areas." (Participant 6)

Participants felt that their role was not to primarily generate prescriptions instead they were keen to communication and interact with patients as part of an accurate assessment and competent prescribing process. Understanding the characteristics of the patient's requirements, strengths and weaknesses that facilitated a more holistic approach to prescribing was identified as important.

"Having a conversation is important because you can have patients with strange reactions to their medicines and if you don't explore it properly you won't know. I find that sometimes the gaps I identify during conversation give me the most information.” (Participant 7)

\subsection{Understanding and consequences of inappropriate prescribing}

The level of understanding regarding inappropriate prescribing was broad and has been condensed into the main areas identified in Table 2.

Table 2. Description of inappropriate prescribing

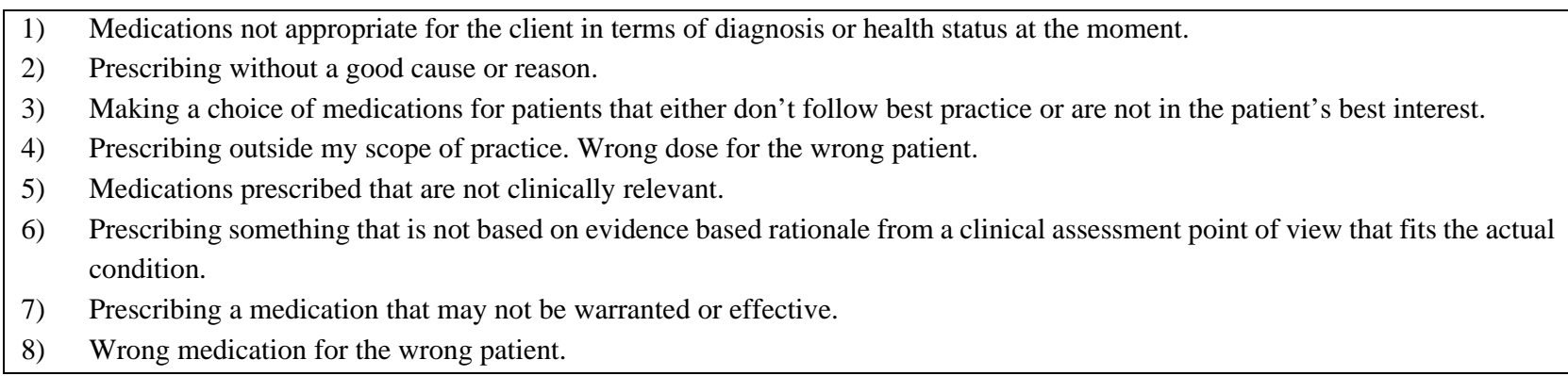

Although not referred to directly prescribing by omission was addressed indirectly when answering questions.

It is an established fact that medication use increases with advancing age. This in turn requires that prescribing for older people represents a range of options and values that attempt to optimize prescribing quality for individual patients.

"Prescribers do not use frailty as a predictor when prescribing. A lot of the medication of older folk are family driven because they want Mom or Dad or whoever to have the same level of care that they have not recognising the physiological changes that occur with aging may not make those medications appropriate." (Partici- pant 4)

Also depending on the level of care, therapies can be viewed from different perspectives.

"Sometimes treatment in hospitals would be a little more aggressive than what we would consider appropriate in primary care." (Participant 7)

All participants identified they had a substantial role to ensure medicines were appropriate. Specifically, interactive approaches were used to combat problems.

"I have a direct involvement because I am educating the residents myself and nursing staff 
plus allied staff. I also review charts as part of the process." (Participant 4)

"I have direct involvement in making sure medications are appropriate we do hundreds of med reviews every year and we do med reconciliation also. I explain to the families and staff the physical and medications review results." (Participant 3)

Participants linked proper assessment to appropriate prescribing through individualised care assessment thereby, ensuring the drug-patient interaction is implicitly included in the prescriptive process.

"I've seen families who were primary care givers for older adults struggling to manage with what appeared to be deteriorating conditions which were actually side effects of medications when assessed." (Participant 7)

Several characteristics of ageing and geriatric medicine affect medication prescribing for older adult people and render the selection of appropriate pharmacotherapy a challenging and complex process that may not result in the desired effect.

"I really don't think there is a black and white answer to prescribing sometimes the patient does not keep up to date with the changes to medications it's not always about the medicines sometimes its human error that causes the problems. We try to do our best, but sometimes problems just happen.” (Participant 4)

Inappropriate prescribing remains a problem in day-to-day practice and despite increased awareness the dynamic nature of the problem requires updating solutions that address constant changing patterns.

"I try to focus on what I do well... and individualise care to reduce risk." (Participant 6)

For prescribing in general it is important that the patient has trust in the prescriber. Trust is also essential for establishing collegial relationships with other healthcare professionals and patients.

"There is human error in everything we do. What people deserve to know is whether it was an error or an omission and the biggest thing people want to know is what are we going to do differently, or if we are going to do anything differently. That's how we tend to manage most everything here." (Participant 5)
Participants were confident that the consequences of inappropriate prescribing could be addressed.

"I think it would be education for all involved but there is a barrier to that because it costs money." (Participant 2)

"So in order to make change we really have to have a complete culture shift and make the prescribers and the whole system aware that seniors require unique care and they are uniquely different form the adult population when it comes to prescribing." (Participant 4)

"I'm the only nurse practitioner within a huge facility ( 485 beds) in my opinion there is work for three in the facility then we could cover and support each other and share the workload and have cover at the weekends. Yes we need more prescribing nurse practitioners." (Participant 3)

“Address polypharmacy we've been talking about it for years but we are only starting to take some action now." (Participant 1)

Polypharmacy was identified as very common among older adults and is often adopted as a strategy to address symptoms, reducing disease-related problems and improving quality of life in the older adult.

"When we look at underlying causes for problematic symptoms it is sometimes due to too many drugs. We have to strip them back to the essential drugs so that the team can get in and treat the patient in a meaningful way." (Participant 5)

Polypharmacy may also be the result of patient and/or family assuming the role of prescriber.

"If over the counter drugs are added (to the medication regime) the patients may present to us with problems that can be difficult to figure out. Education is important and even salads in the summer for someone on warfarin can cause problems.” (Participant 8)

It is unrealistic to expect that the majority of clinicians have enough knowledge about drug-related appropriateness and interactions when prescribing for older people with multimorbidity to avoid errors. However, participants felt that they could err on the side of caution.

"If there is ever a problem I write my cell number on all my prescriptions so if the pharmacist ever has a question they can contact me directly to discuss any possible error." (Participant 5) 
The most effective benefits of prescriptive drug therapy for older adults can only be derived if drugs are prescribed and used appropriately. Participants voiced that combining expert opinions was also an option.

“... attention to detail is required and if I have a problem I will take it to my collaborative practice partner to discuss. I work in a collaborative team so I don't work in isolation it's always good to have colleague around for advice." (Participant 6)

\subsection{The role screening tools play in prescribing for older people}

All participants had experience of using a prescribing appropriate evaluation tool and were familiar with the STOPP/START evaluation tool in particular.

"I used the STOPP/START criteria in my work and clearly identified areas where there is inappropriate prescribing and the need for reevaluation depending on the stage of life." (Participant 4)

Time appeared to be an issue when applying a screening tool with some participants identifying it as cumbersome to apply in the clinical setting. Many practical issues were raised.

"I can really see the benefit of using a medication evaluation tool especially if we had the database that you (the researcher) use. It would save us time and we would get immediate results. Using STOPP/START and applying the criteria manually is just not practical." (Participant 3)

"I think it would play an important role especially if the nurses and doctors were using the same computer based system. We would follow the same structure and have a better result for the patient using the evaluation tool." (Participant 2)

Participants' concerns regarding potential inappropriate prescribing (PIP) also extended to the management of patients' medications from the wider perspective of changing conditions to ensure medications prescribed remain appropriate.

"I love the STOPP/START tool because the research is there in the literature and so easy to share the information and findings. They make us think about leaving people on medications for extended periods of time simply because they saw a cardiologist 15 years ago.” (Participant 3 )
Other participants could see possibilities beyond the initial identification of PIP.

"They are not necessarily looking at just prescribing but gathering data on your patient about their diagnosis, past history, medications, lab tests and activities of daily living a concise history and assessment on each patent documented and easily accessible." (Participant 8)

\section{Discussion}

All participants were knowledgeable regarding inappropriate prescribing and had information about or worked with a prescribing evaluation tool in the past. As with previous research, participants highly rated the use of a prescribing medication evaluation tool, understanding that medication appropriateness can be measured by evaluating the content or quality of a prescribing decision and or the outcome of that decision. ${ }^{[33]}$ Even though there was a number of prescribing evaluation tools available for detecting inappropriate prescribing, the participants had a very good working knowledge of the STOPP/START criteria. This was attributed to the ongoing research using the STOPP/START criteria undertaken by the Pharmacy Department in Dalhousie University, Halifax, in collaboration with the Pharmacy Department in University College Cork, Ireland.

All participants endorsed regular reviews of older adults prescriptions, a practice that is supported by the literature to reduce medications prescribed. ${ }^{[34]}$ Nurse practitioners were aware of the issues surrounding the aging population in their region especially the growing number of older adults that face challenging treatment decisions. This trend makes it even more critical to develop interventions that can improve the decision-making process to ensure appropriate medications are prescribed. ${ }^{[35]}$ In order to facilitate good decision making and depending on cognitive awareness of patient's nurse practitioners included families when necessary through organised family conferences. Including the family in the assessment process opened communication to ensure that patients concerns and wishes regarding medications and treatments are elicited and understood. This is an important additional component of managing medications considering physicians' and patients' perspectives on treatment and associated decisions can sometimes differ. Such differences were identified by Kutner et al. ${ }^{[36]}$ who recognised physicians rank co-morbid conditions and the medical literature as important factors in treatment decision-making, while patients rank family preference, family burden, and physician's opinion as important factors in making treatment decisions. Nurse practitioners with prescriptive authority are adequately placed in practice to promote informed treatment choices that are consistent 
with the patients' personal preference and based on informed decision making. Nonetheless, the balance is fine between medications that improve quality of life for the older adult and medication related problems that place them at risk ${ }^{[37]}$.

Nurse practitioners identified that selecting appropriate medications for use in older adult patients is often complicated by multiple illnesses and multiple medications. The potential is high for drug-drug and drug-disease interactions which the nurse practitioner must bear in mind when choosing a medication or assessing its effectiveness or side effects. ${ }^{[38]}$ The primary factor associated with medicine under use was a lack of health literacy concerning geriatric conditions in those caring for older adults' findings similar to Lang et al. ${ }^{\left[{ }^{[9]}\right.}$ Even though participants indicated that specialisation improved their knowledge, it was focused on a specific condition or system depending on nurse practitioners area of expertise. This posed a considerable challenge for nurse practitioners, because patients who usually presented with problems require a wider understanding of individual diagnosis and differential diagnosis in order to make appropriate medication decisions for them. To ensure patients with multiple problems were appropriately assessed the nurse prescriber utilised the expertise of the multidisciplinary team which according to the literature "utilises individuals from different disciplines working in a team toward a common goal" ${ }^{[40]}$ Internationally such collaboration has led to improved client outcomes such as decreased hospital admissions and timely interventions for older adults. ${ }^{[41,42]}$ However, participants also expressed the importance of combining multidisciplinary care with a medication evaluation tool especially STOPP/START was significant because of its correlation with adverse drug events (ADEs). ${ }^{[43]}$

Much attention has been paid to over-prescribing for older adults nonetheless participants recognised that underprescribing of appropriate medications was also a concern. This is a seriously misdirected practice according to Rochon $^{[44]}$ (2015) because seeking to simply limit the overall number of drugs prescribed to older adults in the name of improving quality of care is incorrect practice. Therefore, a medication evaluation tool used in practice needs to encompass the appropriateness of prescribing which according to Spinewine et al. ${ }^{[45]}$ embraces three values: 1) the preferences of the patient; 2) the scientific and technical rationale of prescribing; and 3) the interests of the community. However, quantifying what the patient wants and serving the best interests of the community can be quite challenging as they can be influenced by societal, economic and family factors. ${ }^{[46]}$

The literature reveals that numerous studies using STOPP/START criteria have been conducted in various patient-care settings to assess prescribing appropriateness. ${ }^{[47-52]}$ However, when using a prescribing evaluation tool, it is important to consider that explicit criteria such as that of STOPP/START do not take into account all factors that define high quality health care for the individuals. The START screening tool for potential prescribing omissions (PPOs) does not allow for factors such as life expectancy, time needed to derive clinical benefit and patient preference as legitimate reasons for under-prescribing. ${ }^{[45]}$ It is the nurse practitioners responsibility to understand the burden of comorbid disease and patient preference which are then taken into account and required to reconcile decisions with the evaluation tool. Applying the STOPP/START evaluation tool may require flexibility, in some cases, what is considered inappropriate according to STOPP/START may not be appropriate for an individual patient for various reasons. ${ }^{[53]}$ To address this, guidelines accompanying the STOPP/START evaluation tool clearly state that the tool does not replace the clinical judgment of the prescriber. ${ }^{[50]}$ There were however, concerns expressed about inconsistent implementations of the evaluation tools and the time required to evaluate patient's medications. According to Ryan et al. ${ }^{[48]}$ this issue was recognised by the research group in the School of Pharmacy, University College Cork and University Hospital Cork who began developing a database to facilitate the use of STOPP/START criteria in day-to-day clinical practice. Furthermore, in 2013 the research group was funded to develop a Software ENgine for the Assessment \& optimization of drug and non-drug Therapy in Older peRsons (SENATOR) a highly-powered and efficient software engine capable of individually screening the clinical status and pharmacological and non-pharmacological therapy of older adults with multimorbidity. The significance of this software to nurse practitioner and other prescribers is that it can define optimal drug therapy, highlight adverse drug reaction risk, indicate best value drug brand for selection and provide advice on appropriate non-pharmacological therapy. A very valuable tool considering the majority of older adults with multimorbidity are managed by healthcare professionals that are not specially trained in geriatric medicine and rehabilitation and may not have access to a geriatrician or specialised nurse practitioner to help with assessments.

In this study, nurse practitioners' knowledge and experience was recognised by senior doctors as supportive within their practices. In addition, the value of nurse practitioners was also considered important because of connection with a range of services and clinical networks that have been emphasised in the literature as primary, speciality and acute services. ${ }^{[54]}$ Participants in this study did not take for granted the referring diagnosis of the GP or hospital department but showed 
initiative and integrity and acted on their advanced knowledge and experience to independently assess their patients. The nurse practitioner then had the confidence and ability to bring a range of clinicians together to develop a package of care that was focussed on the individual patient needs. Utilising this approach helps the nurse practitioner to look beyond the initial clinical problems that presented to focus on the more holistic plan of care for each patient and provide staff with support and motivation. ${ }^{[55]}$ However, building such an integral service required healthcare professionals to broaden their professional standards. This process requires training, discussion, collaboration, and a shared assessment and treatment plan. ${ }^{[56]}$ The fact that the nurse practitioners mentor and are champions for change within organisations is significant for the future development of best practice in elderly care.

The importance of continuing professional development (CPD) and remaining up to date was and issue identified by all participants that required additional support. Positive comments were tempered with a belief that too many demands placed on the nurse practitioner encroach unacceptably on the opportunity to undertake CPD. Specifically, heavy workload and absence of colleagues to cover the work (backfill) prevent uptake of CPD, issues already identified in the literature. ${ }^{[57]}$ Whilst it was acknowledged that a certain amount of learning was achieved "on the job", it was repeatedly put forward in the interviews that formal education and training was necessary to supplement and enhance such learning. Considering the predicted changes of increasing complexity in elderly care ${ }^{[58]}$ it is essential that nurse practitioners engage with CPD and are supported throughout their careers to maintain and develop the knowledge and skills to respond effectively to the needs of patients, service users and the wider public. ${ }^{[59]}$ Especially when viewed in the context of changing demographic patterns of disease in countries across the world and the subsequent impact on health service delivery, preparatory education can only ever be an initial grounding for nurse practitioners.

\section{Limitations}

This study has the limitations specifically related to the use of the qualitative methodology. Among its limitations is the low number and source of the participants drawn from a specific area in Canada, who are not necessarily representative of all
Canadian nurse practitioners, restricting the study's generalisation to other areas or countries. In addition, recruitment of participants for this study was the responsibility of the senior nurse practitioner for the Nova Scotia Region, Canada. All of the participants had previously heard about STOPP/START criteria, because of involvement with research in the clinical practice, which is not representative of the general nurse practitioner population. The sample size of eight although small is acceptable for qualitative research and reached saturation point.

\section{Conclusion}

Nurse practitioners have derived both personal and professional benefits from prescribing and feel better equipped to make decisions and challenge changes if necessary. The potential for prescribing nurse practitioners to contribute positively to address the issues with increasing healthcare demands and associated problems and to improve quality of care in the Canadian health system is substantial given their understanding regarding appropriate and inappropriate medication management.

Nurse practitioners in Nova Scotia, Canada are both competent and confident prescribers and have integrated prescribing effectively within their respective roles. In addition, recognition of their role and contribution to the wider healthcare team is acknowledged but there are still some cautious responses from a number of doctors in practice. Another tangible issues identified is the importance and support required for ongoing CPD. More specifically CPD was identified as a substantial prerequisite for maintaining knowledge and keeping up-to-date with the ever changing pharmaceutical industry and medications available in practice. Management strategies employed in practice were communication, collaboration and collegial relationships to effectively safeguard medications prescribed and reviewed as appropriate for the older adult population. However, the issues surrounding the consequences of inappropriate prescribing were more complex requiring an organisational approach to the interactive management of medications prescribed and reviewed to ensure maximum benefit.

\section{CONFlicts of InTEREST Disclosure}

The authors declare that there is no conflict of interest.

\section{REFERENCES}

[1] Worster A, et al. Understanding the role of the nurse practitioner in Canada. Canadian Journal of Rural Medicine. 2005; 10(2): 89-91. PMid:15842791

Published by Sciedu Press
[2] DiCenso A, et al. Report on the Integration of Primary Health Care Nurse Practitioners into the Province of Ontario. Toronto, ON: Ministry of Health and Long-Term Care. 2003.

[3] DiCenso A, et al. Primary health care nurse practitioners in Canada, 
Contemporary Nurse. 2007; 26(1): 104-115. PMid: 18041990 http: //dx.doi.org/10.5172/conu.2007.26.1.104

[4] McIntosh E, et al. Financially viable nurse-managed centres. The Nurse Practitioner. 2003; 28(3): 46-51. http://dx.doi.org/10. 1097/00006205-200303000-00009

[5] Schober, Affara. Advanced Practice Nursing. Blackwell Publishing Oxford UK. 2006.

[6] Donald F, et al. The Primary Healthcare Nurse Practitioner Role in Canada. Nursing Leadership. 2010; 23(Special Issue): 88-113. http://dx.doi.org/10.12927/cjnl.2013.22271

[7] Gould O, et al. Nurse Practitioners in Canada: Beginnings, Benefits, and Barriers. Journal of the American Academy of Nurse Practitioners. 2007; 19(4): 165-71. PMid:17430537 http://dx.doi.org/1 $0.1111 / \mathrm{j} .1745-7599.2007 .00210 . \mathrm{x}$

[8] Esmail N. Canada's physician supply. Fraser Forum March/April 2011. 2011.

[9] Latter S, Courtenay M. Effectiveness of nurse prescribing: a review of the literature. Journal of Clinical Nursing. 2004; 13: 26 32. PMid:14687290 http://dx.doi.org/10.1046/j.1365-2 702.2003.00839.x

[10] Kaplan L, Brown M. What is "true" professional autonomy? The Nurse Practitioner. 2006; 31(3): 37. http://dx.doi .org/10.10 97/00006205-200603000-00010

[11] Forchuk C, Khor R. Prescriptive authority for nurses: the Canadian perspective. Perspectives in Psychiatric Care. 2009; 45(1): 3 8. PMid:19154247 http://dx.doi.org/10.1111/j.1744-616 3.2009.00194.x

[12] Jehan W, Nelson C. Advanced primary nursing: Liberating the talents. Nursing Management. 2006; 12(9): 20-23. PMid:16475535 http://dx.doi.org/10.7748/nm2006.02.12.9.20.c2042

[13] Stolee, et al. Advanced primary nursing: Liberating the talent. Nursing Management. 2006; 12: 20-23.

[14] Health Service Executive. Guiding Framework for the Implementation of Nurse and Midwifery Prescribing in Ireland. In: CHILDREN, D. O. D. A. (ed.). Dublin. 2008.

[15] Barry M, et al. Projecting the Impact of Demographic Change on the Demand for and Delivery of Health Care in Ireland. The Economic and Social Research Institute. Dublin. 2009.

[16] Gallagher P, Ryan C, Byrne S, et al. STOPP (Screening Tool of Older Persons Prescriptions) and START (Screening Tool to Alert doctors to Right Treatment): Consensus validation. Int J Clin Pharmacol Ther. 2008; 46(2): 72-83. http://dx.doi.org/10.5414/CPP46072

[17] Sitar D, et al. Prescribing pattern for elderly community-dwelling heavy medicinal drug users in Manitoba, Canada and Jamtland, Sweden. J Clin Epidemiol. 1995; 48(6): 825-31. http://dx.doi .org /10.1016/0895-4356 (94)00189-W

[18] Beer M, Ouslander J, Rollingher I, et al. Explicit criteria for determining inappropriate medication use in nursing home residents. Arch Intern Med. 1991; 151: 1825-32. http://dx.doi.org/10.1001 /archinte.1991.00400090107019

[19] Cantrill J, Sibbald B, Buetow S. Indicators of the appropriateness of long term prescribing in general practice in the United Kingdom: consensus development, face and content validity, feasibility and reliability. Qual Health Care. 1998; 7: 130-135. http: //dx.doi.org/10.1136/qshc.7.3.130

[20] Canadian Institute of Health Information. Health Indicators. 2013.

[21] Canadian Institution of Health Research. Personalised Medicine. 2014.

[22] Lowe G, et al. Time to clarify-the value of advancing practice nursing roles in health care. Journal of advanced Nursing Practice. 2012; 68(3): 677-685. PMid:21790738 http://dx.doi.org/10.1111 /j.1365-2648.2011.05790.x
[23] Snowden A, Martin CR. Mental health nurse prescribing: A difficult pill to swallow? Journal of Psychiatric \& Mental Health Nursing. 2010; 17: 543-553. PMid:20633082 http://dx.doi .org/10.11 $11 / j .1365-2850.2010 .01561 . x$

[24] Courtenay M, Carey N, Stenner K, et al. Patients' views of Nurse prescribing: effects on care, concordance and medicine taking. The British Journal of Dermatology. 2011; 164: 396-401. PMid:21054336 http://dx.doi.org/10.1111/j.1365-2133.2010.10119.x

[25] Bowskill D, Timmons S, James V. How do nurse prescribers integrate prescribing in practice: case studies in primary and secondary care. Journal of Clinical Nursing. 2012; 22: 2077-2086. PMid:23186080 http://dx.doi.org/10.1111/j.1365-2702.2012.04338.x

[26] Latter S, Smith A, Blenkinsopp A, et al. Are nurse and pharmacist independent prescribers making clinically appropriate prescribing decisions? An analysis of consultations. Journal of Health Services Research \& Policy. 2012; 17: 149-156. PMid:22734082 http://dx.doi.org/10.1258/jhsrp. 2012.011090

[27] Ben Natan M, Kabaha A, Jackob N, et al. The attitudes of patients with chronic conditions towards nurse prescribing medications. International Nursing Review. 2013; 60: 469-476. PMid:24251939 http://dx.doi.org/10.1111/inr.12043

[28] Wilson J, Bunnell T. A review of the merits of the nurse practitioner role. Nursing Standard. 2007; 21(18): 35-40. PMid:17256666 http://dx.doi.org/10.7748/ns2007.01.21.18.35.c6398

[29] Lopez K, Wills D. Descriptive versus interpretive phenomenology: their contributions to nursing knowledge. Qual Health Res. 2004; 14(5): 726-35. PMid:15107174 http://dx.doi .org/10.1177/1 049732304263638

[30] Smith EM. Telephone interviewing in healthcare research: Summary of the evidence. Nurse Researcher. 2005; 12(3): 32-41. http: //dx.doi.org/10.7748/nr2005.01.12.3.32.c5946

[31] Colaizzi PF. Psychological research as the phenomenologist views it. In: Valle. RS, King M (eds.) Existential phenomenological alternatives for psychology. New York.: Oxford University Press; 1978.

[32] Benner P. Interpretive phenomenology: Embodiment, caring, and ethics in health and illness. Thousand Oaks, CA: Sage Publications; 1994.

[33] O'Connor M, Gallagher P, O'Mahony D. Inappropriate Prescribing. Drugs Aging. 2012; 29(6): 437-452. PMid:22642779 http: //dx.doi.org/10.2165/11632610-000000000-00000

[34] Loganathan M, Singh S, Franklin B, et al. Interventions to optimise prescribing in care homes: Systematic review. Age Ageing. 2011; 40: $150-62$

[35] Tariman J, Berry D, Cochrane B, et al. Physician, Patient and Contextual Factors Affecting Treatment Decisions in Older Adults with Cancer: A Literature Review. Oncol Nurs Forum. 2012; 39(1): E70-E83. PMid:22201670 http://dx.doi.org/10.1188/12.0NF.E70-E 83

[36] Kutner J, Vu K, Prindiville S, et al. Patient age and cancer treatment decisions. Patient and physician views. Cancer Pract. 2000; 8(3): 114-119. http://dx.doi.org/10.1046/j.1523-5394.2000.8 $3004 . \mathrm{x}$

[37] Rocchiccioli J, Sanford J, Caplinger B. Polymedicine and Aging: Enhancing Older Adult Care Through Advanced Practitioners. Journal of Gerontological Nursing. 2007; 33(7): 19-24. PMid:17672165

[38] Herr K. Chronic pain in the older patient: Management strategies. Journal of Gerontological Nursing. 2002; 28(2): 28-34. http: //dx.doi.org/10.3928/0098-9134-20020201-08

[39] Lang P, Hasso Y, Drame M, et al. Potentially inappropriate prescribing including under-use amongst older patients with cognitive or psychiatric co-morbidities. Age and Ageing. 2010; 39: 373- 
381. PMid:20378571 http://dx.doi.org/10.1093/ageing/af q031

[40] Thylefors I, Persson O, Hellstrom D. Team types, perceived efficiency and team climate in Swedish cross-professional teamwork. Journal of Interprofessional Care. 2005; 19: 112-114. PMid:15823885 http://dx.doi.org/10.1080/13561820400024159

[41] Arbon P, Bail K, Eggert M, et al. Reporting a research project on the potential of aged care in the Australian Capital Territory. Journal of Clinical Nursing. 2008; 18: 155-162.

[42] HSE. Cost of Care in Approved Facilities. Department of Health, Dublin Press. 2010. Available from: http://www.hse.ie/eng/services/Find_a_Service/0 lder_People_Services/nhss/costs.html

[43] Hamilton H, Gallagher P, Ryan C, et al. Potentially inappropriate medications defined by STOPP criteria and the risk of adverse drug events in older hospitalized patients. Arch Intern Med. 2015; 171: 1013-19.

[44] Tochon P. Drug prescribing for older adults. 2015. Available from: http://www. uptodate.com/contents/drug-prescri bing-for-older-adults

[45] Spinewine A, Schmader KE, Barber N, et al. Appropriate prescribing in elderly people: how well can it be measured and optimised? Lancet. 2007; 370: 173-184. http://dx.doi.org/10.1016/S01 40-6736 (07) 61091-5

[46] Lam M, Cheung B. The use of STOPP/START criteria as a screening tool for assessing the appropriateness of medications in the elderly population. Expert Review of Clinical Pharmacology. 2012; 5(2): 187-97. PMid:22390561 http://dx.doi.org/10.1586/ecp. 12 . 6

[47] Gallagher P, O'Mahony D. STOPP (Screening Tool of Older Persons' potentially inappropriate Prescriptions): Application to acutely ill elderly patients and comparison with Beers' criteria. Age \& Ageing. 2008; 37(6): 673-679. PMid:18829684 http://dx.doi.org/10. 1093/ageing/afn197

[48] Ryan C, O'Mahony D, Kennedy J, et al. Potentially inappropriate prescribing in an Irish elderly population in primary care. British Journal of Clinical Pharmacology. 2009; 68(6): 936-947. PMid:20002089 http://dx.doi.org/10.1111/j.1365-2125.2009.03531.x

[49] Cahir C, Fahey T, Teeling M, et al. Potentially inappropriate prescribing and cost outcomes for older people: A national population study. British Journal of Clinical Pharmacology. 2010; 69(5): 543552. PMid:20573091 http://dx.doi.org/10.1111/j.1365-2 125.2010.03628.x

[50] Gallagher P, Lang P, Cherubini A, et al. Prevalence of potentially inappropriate prescribing in an acutely ill population of older patients admitted to six European hospitals. European Journal of Clinical Pharmacology. 2011; 67(11): 1175-1188. PMid:21584788 http://dx.doi.org/10.1007/s00228-011-1061-0

[51] Ryan C, O'Mahony D, Kennedy J, et al. Potentially inappropriate prescribing in older residents in Irish nursing homes. Age And Ageing. 2012; 42(1): 116-120. PMid:22832380 http://dx.doi .org /10.1093/ageing/afs068

[52] O'Sullivan D, O'Mahony D, Parsons C, et al. A Prevalence Study of Potentially Inappropriate Prescribing in Irish Long-Term Care Residents. Drugs \& Aging. 2013; 30(1): 39-49. PMid:23229766 http://dx.doi.org/10.1007/s40266-012-0039-7

[53] Jansen P, Jacobus R. Clinical Pharmacology in Old Persons. Scientifica. 2012. PMid:24278735 http://dx.doi.org/10.6064/201 2/723678

[54] Conger M, Plager KA. Advanced nursing practice in rural areas: Connectedness versus disconnectedness. Online Journal of Rural Nursing \& Health Care. 2008; 8(1): 24-38.

[55] Garrubba M, Harris C, Melder A. Clinical Leadership: A literature review to investigate concepts, roles and relationships related to clinical leadership. Centre for Clinical Effectiveness, Southern Health, Melbourne, Australia. 2011.

[56] Veysey BM, Anderson R, Lewis L, et al. Integration of alcohol and other drug, trauma and mental health services'. Alcoholism Treatment Quarterly. 2005; 22(3-4): 19-39. http://dx.doi.org/10. 1300/J020v22n03_02

[57] Gould O, Johnstone D, Wasylkiw L. Nurse Practitioners in Canada: Beginnings, Benefits, and Barriers. Journal of the American Academy of Nurse Practitioners. 2007; 19(4): 165-71. PMid:17430537 http: //dx.doi.org/10.1111/j.1745-7599.2007.00210.x

[58] Canadian Nurses Association. Advanced Nursing practice A National Framework. 2008. Available from: https://www.cna-aiic.ca/ /media/cna/page-conte nt/pdf-en/anp_national_framework_e.pdf

[59] McCormick R. The state of the nation in CPD: a literature review. The Curriculum Journal. 2010; 21(4): 395-412. http://dx.doi.o $\mathrm{rg} / 10.1080 / 09585176.2010 .529643$ 